\title{
The action of selected isothiocyanates on bacterial biofilm prevention and control
}

\author{
Anabela Borges $^{\mathrm{a}, \mathrm{b}}$, Lúcia C. Simões ${ }^{\mathrm{a}, \mathrm{c}}$, Maria J. Saavedra ${ }^{\mathrm{b}}$, Manuel Simões ${ }^{\mathrm{a}, *}$ \\ ${ }^{a}$ LEPAE, Department of Chemical Engineering, Faculty of Engineering, University of Porto, Rua Dr. Roberto Frias, s/n, $4200-465$ Porto, Portugal \\ ${ }^{\mathrm{b}}$ CECAV - Veterinary and Animal Science Research Center, Veterinary Science Department, University of Trás-os-Montes e Alto Douro, Apartado 1013, 5001- \\ 801 Vila Real, Portugal \\ ${ }^{\mathrm{C}}$ IBB - Institute for Biotechnology and Bioengineering, Centre of Biological Engineering, University of Minho, Campus de Gualtar, 4710-057 Braga, Portugal
}

\section{A R T I C L E I N F O}

\section{Article history:}

Received 28 December 2012

Accepted 26 January 2013

Available online 26 February 2013

\section{Keywords:}

Adhesion

Biofilm control

Biofilm prevention

Allylisothiocyanate

2-Phenylethylisothiocyanate

Motility

\begin{abstract}
A B S T R A C T
The activity of two selected isothiocyanates (ITCs), allylisothiocyanate (AITC) and 2-phenylethylisothiocyanate (PEITC) was evaluated on the prevention and control of biofilms formed by Escherichia coli, Pseudomonas aeruginosa, Staphylococcus aureus and Listeria monocytogenes. In addition, the effect of ITCs was also tested on planktonic cell susceptibility, bacterial motility and adhesion. Biofilm prevention and control were tested using a microtiter plate assay and the effect of ITCs was assessed on biofilm mass and metabolic activity. The minimum bactericidal concentration for $E$. coli and $P$. aeruginosa was $1000 \mu \mathrm{g} \mathrm{mL} \mathrm{m}^{-1}$ (AITC) and $>1000 \mu \mathrm{g} \mathrm{mL}^{-1}$ (PEITC), for S. aureus and L. monocytogenes was $>1000 \mu \mathrm{g} \mathrm{mL}^{-1}$ (for both ITCS). AITC caused total inhibition of swimming (P. aeruginosa) and swarming (E. coli) motilities. PEITC caused total inhibition of swimming (E. coli, P. aeruginosa and L. monocytogenes) and swarming (E. coli and P. aeruginosa) motilities. Colony spreading of S. aureus was completely inhibited with PEITC. Adhesion assessed in terms of free energy was less favorable when bacteria were exposed to AITC for E. coli and P. aeruginosa and PEITC for P. aeruginosa. Both ITCs had preventive action on biofilm formation and showed a higher potential to reduce the mass of biofilms formed by the Gram-negative bacteria. AITC and PEITC promoted reductions in biofilm activity higher than $60 \%$ for all the biofilms tested. The overall study emphasizes the potential of ITCs as emergent products to inhibit bacterial motility and prevent/control biofilms of important human pathogenic bacteria.
\end{abstract}

(c) 2013 Elsevier Ltd. All rights reserved.

\section{Introduction}

Antimicrobial resistance is one of the major challenges for the industrial, food and biomedical sectors. The increased resistance of pathogenic microorganisms to the antibacterial agents can be directly attributed to the extreme and inappropriate use of antibiotics and disinfectants (Andersson and Levin, 1999; Guillemot, 1999; Monroe and Polk, 2000; Andersson, 2003). Some infectious diseases are almost untreatable by conventional antibiotic therapy (Dalton et al., 2012). Antimicrobial resistance is worsened when the microorganisms form biofilms (Mah and O’Toole, 2001).

Biofilms are complex multicellular microbial communities irreversibly attached to a surface, enclosed in a matrix of extracellular polymeric substances (EPSs) such as proteins, nucleic acids and polysaccharides, and represent the prevalent mode of microbial life in nature, industrial processes and some infections (Hall-Stoodley et al., 2004; Cos et al., 2010; Toté et al., 2010; Jiang et al., 2011).

\footnotetext{
* Corresponding author. Tel.: +351 225081654

E-mail address: mvs@fe.up.pt (M. Simões).
}

Biofilms are an example of physiological adaptation and are one of the most important sources of bacterial resistance to antimicrobials (Simões, 2011). Bacteria embedded in biofilms are more resistant to antimicrobial products than their planktonic counterparts (Mah and O'Toole, 2001; Stewart and Costerton, 2001; Donlan and Costerton, 2002; Jagani et al., 2009; Cos et al., 2010; Simões et al., 2011b). In addition to the conventional mechanisms of antibiotic resistance found in planktonic cells (efflux pumps, modifying enzymes, and target mutations) (Walsh, 2000; Stewart and Costerton, 2001), there are several mechanisms that protect bacteria in biofilm, particularly: (i) poor penetration or inactivation of antimicrobials in the extracellular polymeric matrix; (ii) an altered (dormant) bacterial metabolic state; (iii) the presence of persister cells; (iv) resistance induced by the antimicrobial itself following the use of sublethal concentrations and the upregulation of efflux pumps (Gilbert et al., 2003; Anderson and O'Toole, 2008). Biofilm resistance is usually multifactorial and may vary from one organism to another (Gilbert et al., 2003; Aslam, 2008). Furthermore, the emergence of antimicrobial resistant bacteria and phenotypes clearly shows that new biofilm control strategies are required (Simões et al., 2006). A better understanding of bacterial tolerance and resistance to antimicrobial 
products has led to new interests in natural antibacterial products which restrict the ability of bacteria to adhere, communicate, and form complex biofilms (Al-Sohaibani and Murugan, 2012). An important strategy to combat the resistance problem involves the discovery and development of new antimicrobials capable to suppressing bacterial resistance mechanisms (Abreu et al., 2012).

Many of the antimicrobial drugs used to effectively treat human disease have been derived from nature (Newman and Cragg, 2007; Brown and Hampton, 2011). Dietary phytochemicals (plant secondary metabolites) are potent bioactive compounds from plant sources with a wide range of effects (Holst and Williamson, 2004). Glucosinolates (GLS) are an important group of phytochemicals present exclusively in the order Capparales and very abundant in Brassicaceae (Syn. Cruciferae) family (Halkier and Du, 1997; Grubb and Abel, 2006; Barbieri et al., 2008; Al-Gendy et al., 2010). This family includes various vegetables such as cabbage, broccoli, cauliflower, horseradish, Brussels sprouts and kohlrabi (Fahey et al., 2001; Holst and Williamson, 2004). More than 120 different GLS are known to occur naturally in plants (Fahey et al., 2003; Clarke, 2010; Berhow et al., 2012). They are grouped into aliphatic, aromatic and indole glucosinolates, based on their chemical structure (Halkier and Gershenzon, 2006). These phytochemicals are usually broken down through hydrolysis catalyzed by myrosinase ( $\beta$-thioglucosidase enzyme), released from damaged plant cells, in to numerous biologically active products such as isothiocyanates (ITCs), nitriles, epithionitriles and thiocyanates (Fahey et al., 2001; Hong and Kim, 2008; Aires et al., 2009b). GLS and their hydrolysis products (GHP), in particular ITCs, have long been known to have biological activities including various pharmaceutical benefits to human health (anticarcinogenic, antimicrobial and antioxidant properties) and plant defence (against insects, fungi and microbial infections) (Hong and Kim, 2008; D'Antuono et al., 2009; Saavedra et al., 2010). The effects of GLS on the quality of both human and animal foods, and the emerging evidence that brassica vegetables may have important anticarcinogenic effects associated with the biological activity of GHP provides a good reason for the increased interest in natural biosynthetic pathways of these compounds. In this work, the ability of two ITC's (allylisothiocyanate and 2-phenylethylisothiocyanate) to control biofilms formed by four bacterial species of potential biomedical concern (Escherichia coli, Pseudomonas aeruginosa, Staphylococcus aureus and Listeria monocytogenes) was evaluated. In addition, these ITCs were also tested in planktonic growth control and in their ability to act on biofilm prevention, motility inhibition and on bacterial-surface free energy of adhesion.

\section{Material and methods}

\subsection{Microorganisms and culture conditions}

Two Gram-negative bacteria, E. coli CECT 434, P. aeruginosa ATCC 10145, and two Gram-positive bacteria, S. aureus CECT 976 and $L$. monocytogenes ATCC 15313, were used. These bacteria were previously used as model microorganisms for antimicrobial tests with phytochemical products (Simões et al., 2008a; Saavedra et al., 2010; Borges et al., 2012).

\subsection{Isothiocyanates}

Allylisothiocyanate (AITC) and 2-phenylethylisothiocyanate (PEITC) (Fig. 1) were obtained from Sigma-Aldrich (Portugal). Phytochemicals are routinely classified as antimicrobials on the basis of susceptibility tests that produce inhibitory concentrations in the range of $100-1000 \mu \mathrm{g} \mathrm{mL}^{-1}$ (Simões et al., 2009). In this work, each product was tested at a concentration of $1000 \mu \mathrm{g} \mathrm{mL}^{-1}$

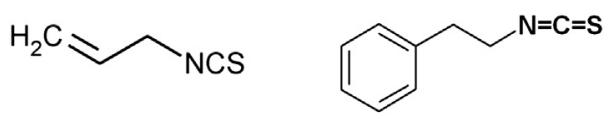

A

B

Fig. 1. Chemical structures of AITC (A) and PEITC (B).

in dimethyl sulfoxide (DMSO, Sigma), for motility, adhesion and biofilm tests. Negative controls were performed with DMSO. AITC and PEITC were selected based on their strong antimicrobial activity when compared with a panel of structurally distinct phytochemicals (Aires et al., 2009a,b; Saavedra et al., 2010).

\subsection{Dose response curves}

Dose response curves were performed with different concentrations $\left(0,100,500\right.$ and $\left.1000 \mu \mathrm{g} \mathrm{mL}^{-1}\right)$ of AITC and PEITC in Mueller-Hinton broth (MHB) (Merck, Germany), at $30{ }^{\circ} \mathrm{C}$, in 96-wells flat-bottomed polystyrene (PS) tissue culture plates with a lid (Orange Scientific, USA) using a total volume of $200 \mu \mathrm{L}$. An inoculum of $1 \times 10^{8} \mathrm{CFU} / \mathrm{mL}$ of bacteria, in the log phase of growth, was used. After $1 \mathrm{~h}$ exposure to the ITCs, an aliquot of $50 \mu \mathrm{L}$ of planktonic suspension was collected, according to the procedure described by Simões et al. (2008a). The number of bacteria in the samples was determined by making serial dilutions in saline solution $(0.85 \% \mathrm{NaCl})$. Thirty $\mu \mathrm{L}$ of each dilution were plated on Mueller-Hinton agar (MHA) plates and incubated overnight, at $30{ }^{\circ} \mathrm{C}$. Colonies were counted after $24 \mathrm{~h}$ incubation period. Three independent experiments were performed for each condition tested. The minimum bactericidal concentration (MBC) was taken as the lowest concentration of ITCs at which no CFU were detected on solid medium (Ferreira et al., 2011; Borges et al., 2012).

\subsection{Motility assays}

Overnight cultures grown on Luria-Bertani broth (LBB) (Merck, Germany), at $30{ }^{\circ} \mathrm{C}$ and under agitation (150 rpm) were used to characterize bacterial motility. Fifteen $\mu \mathrm{L}$ of these cultures were applied in the center of plates containing $1 \%$ tryptone, $0.25 \% \mathrm{NaCl}$, and $0.3 \%, 0.7 \%$ or $1.5 \%(\mathrm{w} / \mathrm{v})$ agar for swimming/colony spreading, swarming and twitching motilities, respectively (Butler et al., 2010; Stickland et al., 2010). Colony spreading was assessed for $S$. aureus and twitching motility was only assessed for P. aeruginosa. The use of different concentrations of agar (the medium porosity directly related to the concentration of agar, so various levels of bacterial diffusion can be selected) enables the characterization of different types of bacterial motility. AITC and PEITC at $1000 \mu \mathrm{g} \mathrm{mL}{ }^{-1}$ were incorporated in the growth medium (tempered at $45^{\circ} \mathrm{C}$ ). Negative controls were performed with medium without ITCs. Plates were incubated at $30{ }^{\circ} \mathrm{C}$ and the diameter $(\mathrm{mm})$ of the motility halos were measured at 24,48 and $72 \mathrm{~h}$. Three plates were used to evaluate the motility of each bacterium.

\subsection{Free energy of adhesion}

The free energy of adhesion $\left(\Delta G_{\text {iwl }}^{\text {Tot }}\right)$ between the bacterial cells and PS surfaces was assessed according to the procedure described by Simões et al. (2008b). After overnight growth in MHB, the cells were centrifuged and resuspended in saline solution to obtain an $\mathrm{OD}_{640}$ of $0.2 \pm 0.02\left(1 \times 10^{8} \mathrm{CFU} / \mathrm{mL}\right)$. One hundred $\mathrm{mL}$ of this suspension was collected and exposed to $1000 \mu \mathrm{g} \mathrm{mL}^{-1}$ during $1 \mathrm{~h}$. Cell suspensions without ITCs were used as controls. To ascertain the bacterial surface properties, lawns of bacteria were prepared as described by Busscher et al. (1984). PS surfaces were prepared for characterization by immersion in a solution of commercial 
detergent (Sonasol Pril, Henkel Ibérica S. A.) in ultrapure water for $30 \mathrm{~min}$. After rising with ultrapure water, the surfaces were dried at $65^{\circ} \mathrm{C}$ for $3 \mathrm{~h}$.

The contact angles of the bacteria and the PS were determined by sessile drop contact angle measurements, using a model OCA 15 Plus (DATAPHYSICS, Germany) that allowed image acquisition and data analysis. The surface tension components of bacteria and PS were obtained by measuring the contact angles with three pure liquids. These measurements were carried out at room temperature $\left(25 \pm 2{ }^{\circ} \mathrm{C}\right.$ ) using water, formamide and $\alpha$-bromonaphthalene (Sigma) as reference liquids. The surface tension components of the reference liquids were taken from the literature (Janczuk et al., 1993). Contact angle data were obtained from at least 25 determinations for each liquid and for each experiment. Afterward, the hydrophobicity of bacteria and the PS surfaces was evaluated from contact angle measurements by the method of Van Oss et al. $(1987,1988)$. The degree of hydrophobicity of a given material (i) is expressed as the free energy of interaction between two entities of that material immersed in water $(\mathrm{w})-\left(\Delta \mathrm{G}_{\text {iwi }} \mathrm{mJ} \mathrm{m^{-2 }}\right) . \Delta \mathrm{G}_{\text {iwi }}$ was calculated from the surface tension components of the interacting entities, according to the equation:

$$
\begin{aligned}
\Delta G_{i w i}= & -2\left(\sqrt{\gamma_{i}^{\mathrm{LW}}}-\sqrt{\gamma_{\mathrm{w}}^{\mathrm{LW}}}\right)^{2}+4\left(\sqrt{\gamma_{\mathrm{i}}^{+} \gamma_{\mathrm{w}}^{-}}+\sqrt{\gamma_{\mathrm{i}}^{-} \gamma_{\mathrm{w}}^{+}}\right. \\
& \left.-\sqrt{\gamma_{\mathrm{i}}^{+} \gamma_{\mathrm{i}}^{-}}-\sqrt{\gamma_{\mathrm{w}}^{+} \gamma_{\mathrm{w}}^{-}}\right)
\end{aligned}
$$

where $\gamma^{\mathrm{LW}}$ accounts for the Lifshitz-van der Waals component of the surface free energy and $\gamma^{+}$and $\gamma^{-}$are the electron acceptor and electron donor parameters, respectively, of the Lewis acid-base component $\left(\gamma^{\mathrm{AB}}\right)$, with $\gamma^{\mathrm{AB}}=2 \sqrt{\gamma^{+} \gamma^{-}}$. The surface tension components were estimated by the simultaneous resolution of three equations of the type:

$$
(1+\cos \theta) \gamma_{\mathrm{i}}^{\mathrm{Tot}}=2\left(\sqrt{\gamma_{\mathrm{s}}^{\mathrm{LW}} \gamma_{\mathrm{i}}^{\mathrm{LW}}}+\sqrt{\gamma_{\mathrm{s}}^{+} \gamma_{\mathrm{i}}^{-}}+\sqrt{\gamma_{\mathrm{s}}^{-} \gamma_{\mathrm{i}}^{+}}\right)
$$

where $\theta$ is the contact angle and $\gamma^{\text {Tot }}=\gamma^{\mathrm{LW}}+\gamma^{\mathrm{AB}}$. When studying the interaction (free energy of adhesion $\left(\Delta G_{\text {iwl }}^{\text {Tot }}\right)$ between substances $i$ and I that are immersed or dissolved in water, the total interaction energy, $\Delta \mathrm{G}_{\mathrm{iwl}}^{\mathrm{Tot}}$, can be expressed as:

$$
\begin{aligned}
\Delta \mathrm{G}_{\mathrm{iwI}}^{\mathrm{Tot}}= & \gamma_{\mathrm{iI}}^{\mathrm{LW}}-\gamma_{\mathrm{iw}}^{\mathrm{LW}}-\gamma_{\mathrm{IW}}^{\mathrm{LW}}+2\left[\sqrt{\gamma_{\mathrm{w}}^{+}}\left(\sqrt{\gamma_{\mathrm{i}}^{-}}+\sqrt{\gamma_{I}^{-}}-\sqrt{\gamma_{\mathrm{w}}^{-}}\right)\right. \\
& \left.+\sqrt{\gamma_{\mathrm{w}}^{-}}\left(\sqrt{\gamma_{\mathrm{i}}^{+}}+\sqrt{\gamma_{I}^{+}}-\sqrt{\gamma_{\mathrm{w}}^{+}}\right)-\sqrt{\gamma_{i}^{+} \gamma_{I}^{-}}-\sqrt{\gamma_{i}^{-} \gamma_{I}^{+}}\right]
\end{aligned}
$$

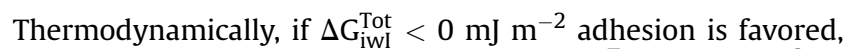
whereas adhesion is not expected to occur if $\Delta G_{\text {iwl }}^{\text {Tot }}>0 \mathrm{~mJ} \mathrm{~m}^{-2}$.

\subsection{Biofilm formation}

Biofilms were developed according to the modified microtiter plate test proposed by Stepanović et al. (2000). Briefly, a sterile 96-wells flatbottomed PS tissue culture plates with a lid were filled with $200 \mu \mathrm{L}$ of bacterial suspension with a density of $1 \times 10^{8}$ cells $\mathrm{mL}^{-1}$. Negative control wells contained MHB without adding any bacterial cells. The plates were incubated for $24 \mathrm{~h}$ at $30^{\circ} \mathrm{C}$ and agitated at $150 \mathrm{rpm}$.

\subsubsection{Biofilm prevention}

Overnight cultures in MHB supplemented with AITC and PEITC at $1000 \mu \mathrm{g} \mathrm{mL}{ }^{-1}$ were grown at $30{ }^{\circ} \mathrm{C}$ and $150 \mathrm{rpm}$. Those cells were used to assess their ability to form biofilms in the microtiter plates, as previously described. Biofilms ( $24 \mathrm{~h}$ aged) were characterized in terms of biomass formation and metabolic activity.
Final results are presented as percentage of biofilm reduction and inactivation.

The ability of bacteria to form biofilms was also ranked according to the scheme proposed by Stepanović et al. (2000) as follow: non biofilm producer $(0)$ : $\mathrm{OD} \leq \mathrm{ODc}$; weak biofilm producer $(+)$ : ODc $<$ OD $\leq 2 \times$ ODc; moderate biofilm producer $(++)$ : $2 \times$ ODc $<$ OD $\leq 4 \times$ ODc; strong biofilm producer $(+++)$ : $4 \times$ ODc $<$ OD. This classification was based upon the cut-off of the optical density (ODc) values, from biomass quantification (crystal violet staining) defined as three standard deviation (SD) values above the mean OD of the negative control.

\subsubsection{Biofilm control}

To determine whether the ITCs had effects on biofilm control, microtiter plates with $24 \mathrm{~h}$ aged biofilms were exposed to $1000 \mu \mathrm{g} \mathrm{mL}^{-1}$ of AITC or PEITC, according to Simões et al. (2010b). One hour after exposure, the biofilms were analyzed in terms of biomass and metabolic activity and the results are presented as percentage of biofilm reduction and inactivation.

\subsubsection{Biofilm mass quantification by crystal violet staining}

The biofilm mass was quantified using crystal violet (Merck, Portugal) staining, according to Simões et al. (2010b). The absorbance was measured at $570 \mathrm{~nm}$ using a Microplate Reader (Spectramax M2e, Molecular Devices, Inc.). All tests were performed in triplicate with three repeats.

Biofilm removal was given by:

$\% B R=\frac{O D_{C}-O D_{W}}{O D_{C}} \times 100$

where \%BR is the percentage of biofilm removal, $O D_{C}$ is the $O D_{570 n m}$ value of biofilms non exposed to ITCs and $O D_{W}$ is the $O D_{570 \mathrm{~nm}}$ value for biofilm exposed to AITC or PEITC.

\subsubsection{Biofilm metabolic activity quantification by alamar blue assay}

The modified alamar blue (7-hydroxy-3H-phenoxazin-3-one10-oxide) (Sigma-Aldrich) microtiter plate assay was applied to determine the bacterial activity of the cells as reported by Sarker et al. (2007). Alamar blue staining was described as a reliable and reproducible method for evaluating biofilm susceptibility (Pettit et al., 2009). For the staining procedure, fresh MHB $(190 \mu \mathrm{L})$ was added to the plates. To each well $10 \mu \mathrm{L}$ of alamar blue $(400 \mu \mathrm{M})$ indicator solution was added. Plates were incubated during $20 \mathrm{~min}$ in darkness and room temperature (RT). Fluorescence was measured at $\lambda_{\text {excitation }}=570 \mathrm{~nm}$ and $\lambda_{\text {emission }}=590 \mathrm{~nm}$ using a Microplate Reader (Spectramax M2e, Molecular Devices, Inc.).

The percentage of biofilm inactivation was given by:

$\% B I=\frac{F I_{C}-F I_{W}}{F I_{C}} \times 100$

where \%BI is the percentage of biofilm inactivation, $\mathrm{FI}_{C}$ is the fluorescence intensity of biofilms non exposed to ITCs and $\mathrm{FI}_{W}$ is the fluorescence intensity value for biofilms exposed to AITC or PEITC.

\subsection{Statistical analysis}

The data were analyzed using the statistical program SPSS version 17.0 (Statistical Package for the Social Sciences). The mean and standard deviation within samples were calculated for all cases. At least three independent experiments were performed for each condition tested. All data were analyzed by the application of the non-parametric Wilcoxon test (confidence level $\geq 95 \%$ ). 


\section{Results}

The action of two selected ITCs, AITC and PEITC, was assessed on biofilm prevention and control of four pathogenic bacteria. Antimicrobial tests with planktonic bacteria were performed in order to understand the antimicrobial potential of AITC and PEITC. In addition, the effect of ITCs was also tested on bacterial motility and adhesion.

The MBC for E. coli and P. aeruginosa was $1000 \mu \mathrm{g} \mathrm{mL}^{-1}$ for AITC and $>1000 \mu \mathrm{g} \mathrm{mL} \mathrm{m}^{-1}$ for PEITC (Fig. 2). Both ITCs had MBC $>1000 \mu \mathrm{g} \mathrm{mL}^{-1}$ for $S$. aureus and L. monocytogenes. The dose response behavior is only statistically $\operatorname{similar}(P>0.05)$ for $S$. aureus and L. monocytogenes when exposed to AITC (Fig. 2a).

The ability of AITC and PEITC at $1000 \mu \mathrm{g} \mathrm{mL}^{-1}$ to interfere with swimming, swarming and twitching motilities of $P$. aeruginosa, swimming and swarming of E. coli and L. monocytogenes and colony spreading of $S$. aureus was investigated (Table 1 ). The swimming motility of E. coli, L. monocytogenes and P. aeruginosa increased from 24 to $48 \mathrm{~h}(P<0.05)$ as well as the twitch motility of $P$. aeruginosa. The same effect was observed for colony spreading of $S$. aureus from 24 to 72 h. A significant time-increase in swimming motility was verified for $E$. coli, the bacteria with the highest swimming motility values for all the sampling times. The application of AITC and PEITC promoted total inhibition in swimming, swarming and twitching motilities of $P$. aeruginosa, $24 \mathrm{~h}$ after inoculation and a significant decrease was observed with AITC and PEITC in swimming motility 48 and $72 \mathrm{~h}$ later $(P<0.05)$. The more complex type of surface motility, i.e. swarming, was completely inhibited for E. coli and $P$. aeruginosa with both AITC and PEITC for all sampling times $(P<0.05)$. The same result was verified for swimming motility of E. coli with application of PEITC $(P<0.05)$. In addition, the swimming motility of $E$. coli and $L$. monocytogenes was reduced by AITC $(P<0.05)$. PEITC caused total inhibition of the swimming motility of $L$. monocytogenes 24,48 and $72 \mathrm{~h}$ after inoculation $(P<0.05)$. For
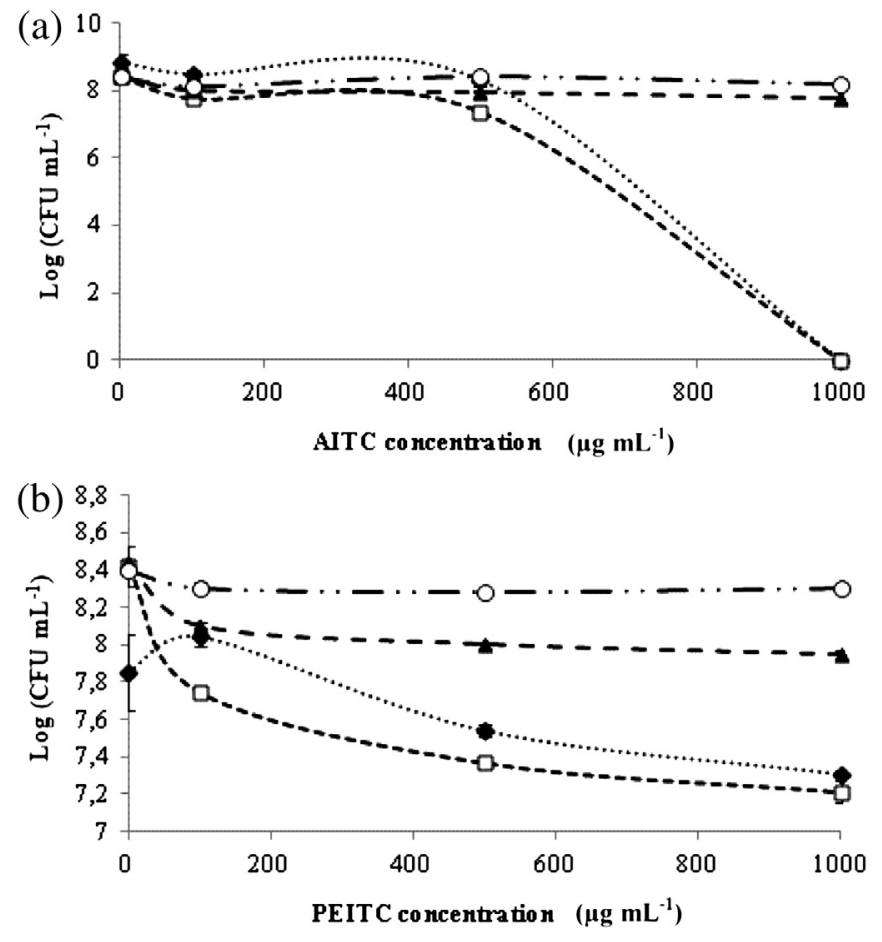

Fig. 2. Log CFU $\mathrm{mL}^{-1}$ for E. coli $(\bullet)$, P. aeruginosa ( $\left.\square\right)$, S. aureus ( $\Delta$ ) and L. monocytogenes $(O)$ as function of AITC (a) and PEITC (b) concentration $(0,100,500$, and $1000 \mu \mathrm{g} \mathrm{mL}^{-1}$ ) after an $1 \mathrm{~h}$ exposure period. The means \pm SD for at least three replicates are illustrated.
S. aureus, colony spreading was reduced by AITC and completely inhibited with PEITC for all the sampling times $(P<0.05)$. In general, PEITC was more efficient in motility reduction than AITC $(P<0.05)$.

Regarding to the adhesion results (Table 2) the Gram-positive bacteria tested and $E$. coli had no theoretical thermodynamic ability to adhere to $\mathrm{PS}\left(\Delta \mathrm{G}_{\mathrm{iwl}}^{\mathrm{Tot}}>0 \mathrm{~mJ} \mathrm{~m}^{-2}\right)$. Only for $P$. aeruginosa the free energy of adhesion was $<0 \mathrm{~mJ} \mathrm{~m}^{-2}$. L. monocytogenes had the highest $\Delta G_{\text {iwI }}^{\text {Tot }}$ value (less prone to adhere to PS). Only for E. coli with AITC and P. aeruginosa with both ITCs, it was observed increase of the $\Delta \mathrm{G}_{\mathrm{iwI}}^{\mathrm{Tot}}$ values, i.e. there was a decreased in the thermodynamic adhesion potential. For the other bacteria the $\Delta G_{\text {iwl }}^{\text {Tot }}$ values decreased due to ITCs. This decrease was only significant for E. coli treated with PEITC and L. monocytogenes with both ITCs $\left(\Delta G_{i w I}^{\text {Tot }}<0 \mathrm{~mJ} \mathrm{~m}^{-2}\right)$. In general, the application of ITCs on Grampositive bacteria increased the thermodynamic adhesion potential, while the opposite occurred for these Gram-negative (except for E. coli with PEITC).

In order to ascertain the potential of AITC and PEITC on biofilm prevention, planktonic bacteria were grown in the presence of ITCs and used to form biofilms on PS microtiter plates (Fig. 3a). PEITC had no preventive effects in biofilm formation by $L$. monocytogenes $(P>0.05)$. However, significant prevention in biofilm formation was verified for this bacterium with AITC $(61 \%)(P<0.05)$. The opposite effect was found for $S$. aureus with AITC. This product had no prevention on biomass formation, and PEITC (75\%) had significant preventive action in $S$. aureus biofilm formation $(P<0.05)$. Total biofilm prevention was only observed for E. coli with AITC. AITC had higher preventive effects than PEITC $(P<0.05)$ on biofilm formation by E. coli (AITC - 100\%; PEITC - 16\%) and P. aeruginosa (AITC - 90\%; PEITC - 37\%).

A ranking of biofilm formation was produced according to Stepanović et al. (2000) classifying bacteria as non-biofilm producers $(0)$, weak biofilm producers $(+)$, moderate biofilm producers $(++)$, or strong biofilm producers $(+++)$ (Table 3$)$. E. coli and $P$. aeruginosa showed a strong biofilm producing ability. L. monocytogenes presented moderate biofilm formation ability and S. aureus formed weak biofilms. When the biofilms were formed in the presence of ITCs, a different biofilm preventive behavior was observed (Table 3 ). AITC had a complete preventive action on $P$. aeruginosa and L. monocytogenes biofilms (from strong and moderate biofilm producers to non-biofilm producers, respectively); a preventive action on $E$. coli biofilms was observed (strong to weak); and no preventive action on S. aureus biofilms was observed. On the other hand, PEITC had preventive action only on S. aureus biofilms (weak to non-biofilm producer) and no preventive effect on biofilm formation by the other bacteria.

In terms of metabolic activity, the analysis of biofilms formed by planktonic bacteria grown in the presence of ITCs (Fig. 3b) shows that AITC (87\% for E. coli; $99 \%$ for P. aeruginosa and L. monocytogenes; 96\% for S. aureus) and PEITC (100\% for E. coli; 93\% for P. aeruginosa; $90 \%$ for S. aureus and $97 \%$ for $L$. monocytogenes) had high effects on metabolic activity reduction for all the biofilms tested.

The ability of AITC and PEITC to control $24 \mathrm{~h}$ aged biofilms was analyzed based on their effects on biomass (Fig. 4a) and metabolic activity (Fig. 4b). Total biofilm mass removal was not achieved with AITC or PEITC. Both ITCs promoted biofilm mass reduction lower than $45 \%$, for all the biofilms tested. The highest reduction in biomass was found for $E$. coli with both ITCs $(P<0.05)$. PEITC was more active than AITC to remove E. coli, P. aeruginosa and $S$. aureus biofilms $(P<0.05)$. In terms of metabolic activity, AITC and PEITC promoted reductions higher than $80 \%$ for all the biofilms tested, except for P. aeruginosa (reduction of approximately 70\%). PEITC had a moderately higher effect on metabolic inhibition than AITC for all the biofilms $(P<0.05)$, except for these of $L$. monocytogenes. 
Table 1

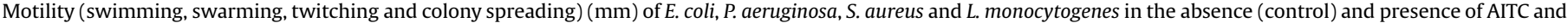
PEITC.

\begin{tabular}{|c|c|c|c|c|c|c|c|c|c|c|c|c|c|}
\hline & & \multicolumn{4}{|l|}{ Control } & \multicolumn{4}{|l|}{ AITC } & \multicolumn{4}{|l|}{ PEITC } \\
\hline & & Swim & Swarm & Twitch & $\begin{array}{l}\text { Colony } \\
\text { spreading }\end{array}$ & Swim & Swarm & Twitch & Colony spreading & Swim & Swarm & Twitch & $\begin{array}{l}\text { Colony } \\
\text { spreading }\end{array}$ \\
\hline \multirow[t]{4}{*}{$24 \mathrm{~h}$} & E. coli & $41 \pm 1.0$ & $9.0 \pm 0.0$ & - & - & $20 \pm 1.0$ & $8.0 \pm 0.0$ & - & - & $8.0 \pm 0.0$ & $8.0 \pm 0.0$ & - & - \\
\hline & P. aeruginosa & $17 \pm 0.0$ & $9.0 \pm 0.0$ & $9.7 \pm 0.6$ & - & $8.0 \pm 0.0$ & $8.0 \pm 0.0$ & $8.0 \pm 0.0$ & - & $8.0 \pm 0.0$ & $8.0 \pm 0.0$ & $8.0 \pm 0.0$ & - \\
\hline & S. aureus & - & - & - & $20 \pm 0.0$ & - & - & - & $13 \pm 1.1$ & - & - & - & $8.0 \pm 0.0$ \\
\hline & L. monocytogenes & $19 \pm 0.6$ & $8.0 \pm 0.0$ & - & - & $10 \pm 0.6$ & $8.0 \pm 0.0$ & - & - & $8.0 \pm 0.0$ & $8.0 \pm 0.0$ & - & - \\
\hline \multirow[t]{4}{*}{$48 \mathrm{~h}$} & E. coli & $85 \pm 0.0$ & $9.0 \pm 0.0$ & - & - & $52 \pm 1.1$ & $8.0 \pm 0.0$ & - & - & $8.0 \pm 0.0$ & $8.0 \pm 0.0$ & - & - \\
\hline & P. aeruginosa & $30 \pm 0.6$ & $11 \pm 0.0$ & $12 \pm 0.0$ & - & $17 \pm 1.1$ & $8.0 \pm 0.0$ & $8.0 \pm 0.0$ & - & $15 \pm 3.2$ & $8.3 \pm 0.6$ & $8.7 \pm 0.6$ & - \\
\hline & S. aureus & - & - & - & $28 \pm 0.0$ & - & - & - & $21 \pm 2.7$ & - & - & - & $8.0 \pm 0.0$ \\
\hline & L. monocytogenes & $27 \pm 0.0$ & $8.0 \pm 0.0$ & - & - & $17 \pm 1.1$ & $8.0 \pm 0.0$ & - & - & $8.0 \pm 0.0$ & $8.0 \pm 0.0$ & - & - \\
\hline \multirow[t]{4}{*}{$72 \mathrm{~h}$} & E. coli & $85 \pm 0.0$ & $9.3 \pm 0.6$ & - & - & $85 \pm 0.0$ & $8.0 \pm 0.0$ & - & - & $8.0 \pm 0.0$ & $8.0 \pm 0.0$ & - & - \\
\hline & P. aeruginosa & $64 \pm 1.1$ & $11 \pm 0.0$ & $12 \pm 0.0$ & - & $42 \pm 8.0$ & $8.0 \pm 0.0$ & $8.0 \pm 0.0$ & - & $18 \pm 2.6$ & $8.3 \pm 0.6$ & $8.7 \pm 0.6$ & - \\
\hline & S. aureus & - & - & - & $35 \pm 0.0$ & - & - & - & $29 \pm 0.6$ & - & - & - & $8.0 \pm 0.0$ \\
\hline & L. monocytogenes & $33 \pm 0.6$ & $8.0 \pm 0.0$ & - & - & $26 \pm 1.7$ & $8.0 \pm 0.0$ & - & - & $8.0 \pm 0.0$ & $8.0 \pm 0.0$ & - & - \\
\hline
\end{tabular}

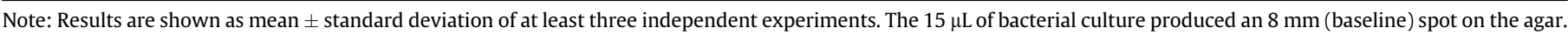

\section{Discussion}

The interest in antimicrobials derived from natural sources has increased in the last years due to the accepted safe status of these compounds (Lin et al., 2000b). It is recognized that some of these molecules benefit health by preventing the risk of some diseases (Prior and Cao, 2000; Aires et al., 2009a,b; Saavedra et al., 2010). ITCs occur naturally in plants and are released during consumption of cruciferous vegetables. These compounds have been demonstrated to possess health-beneficial effects (Conaway et al., 2005; Troncoso et al., 2005; Cartea and Velasco, 2008; Munday et al., 2008; Al-Gendy et al., 2010; Sofrata et al., 2011; Zhang, 2012). The antimicrobial activity of the AITC and PEITC has been predominantly demonstrated against bacteria in planktonic states (Lin et al., 2000a; Masuda et al., 2001; Jang et al., 2010; Saavedra et al., 2010; Chen et al., 2012). In fact, the antimicrobial effects on the biofilm control potential by ITCs are scarce (De Saravia et al., 2003; Guiamet and Gómez De Saravia, 2005; Zou et al., 2012). The antimicrobial mode of action of ITCs is attributed to the binding to sulfhydryl groups on active sites of enzymes important to microbial growth and survival. This leads to reductions in the cellular levels of important thiol groups leading to formation of oxygen and other free-radicals (Kolm et al., 1995; Jacob and Anwar, 2008; Aires et al., 2009a).

In this study, the analysis of dose response curves shows that the $\mathrm{MBC}$ for E. coli and P. aeruginosa was $1000 \mu \mathrm{g} \mathrm{mL} \mathrm{L}^{-1}$ with AITC and $>1000 \mu \mathrm{g} \mathrm{mL}^{-1}$ with PEITC and for S. aureus and L. monocytogenes was $>1000 \mu \mathrm{g} \mathrm{mL} \mathrm{mL}^{-1}$, with both ITCs. In a previously study performed by Jang et al. (2010), PEITC had growth inhibitory effects against several bacterial pathogens, namely $P$. aeruginosa, S. aureus and L. monocytogenes. ITCs from seeds of Sinapis alba L. (white mustard), containing phenethyl, benzyl and benzoyl groups demonstrated significant antimicrobial activity against harmful intestinal bacteria (Bifidobacterium bifidum, Bifidobacterium breve, Bifidobacterium longum, Clostridium difficile, Clostridium perfringens,

Table 2

Adhesion potential of bacteria to PS.

\begin{tabular}{lcccc}
\hline & \multicolumn{4}{l}{$\Delta \mathrm{G}_{\mathrm{iWI}}^{\mathrm{TOT}}\left(\mathrm{mJ} \mathrm{m}^{-2}\right)$} \\
\cline { 2 - 5 } & E. coli & P. aeruginosa & S. aureus & L. monocytogenes \\
\hline Control & $4.7 \pm 0.5$ & $-2.9 \pm 0.3$ & $3.1 \pm 0.7$ & $5.4 \pm 1.2$ \\
AITC & $7.8 \pm 0.3$ & $6.9 \pm 0.6$ & $1.5 \pm 0.4$ & $-12.0 \pm 0.2$ \\
PEITC & $-2.0 \pm 1.3$ & $9.4 \pm 0.9$ & $2.3 \pm 0.8$ & $-43.4 \pm 1.4$ \\
\hline
\end{tabular}

Note: $\Delta \mathrm{G}_{\mathrm{iWI}}^{\mathrm{TOT}}<0 \mathrm{~mJ} \mathrm{~m}^{-2}-$ thermodynamic favorable adhesion; $\Delta \mathrm{G}_{\mathrm{iWI}}^{\mathrm{TOT}}>0 \mathrm{~mJ} \mathrm{~m}^{-2}-$ thermodynamic unfavorable adhesion.
E. coli, Lactobacillus acidophilus, and Lactobacillus casei) (Kim and Lee, 2009). Others reports (Lin et al., 2000a; Rhee et al., 2003) shown that AITC had high bactericidal activity against many foodborne pathogens, including L. monocytogenes, S. aureus, Salmonella enterica serovar Typhimurium, and E. coli 0157:H7. Moreover, strong activity was obtained by Shin et al. (2004), with AITC from
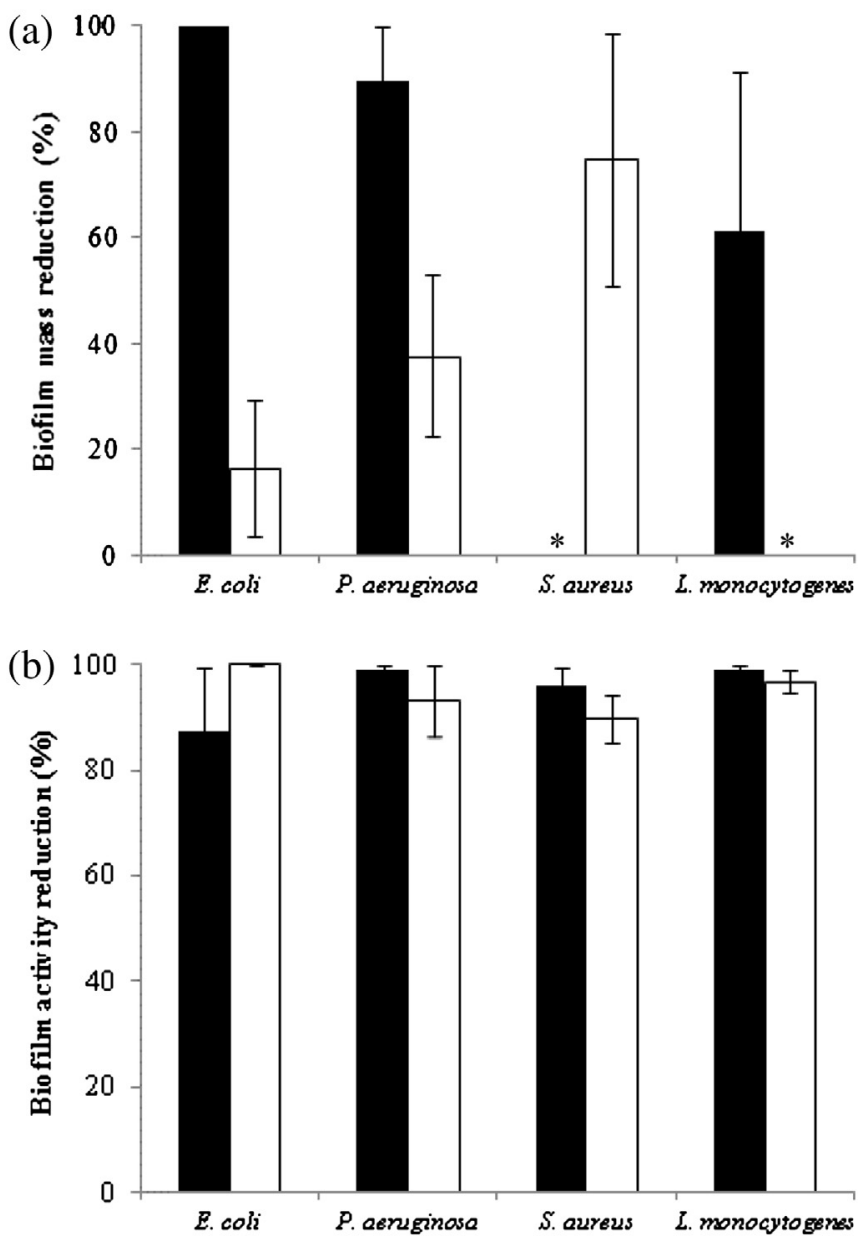

Fig. 3. Preventive action of AITC ( $\square$ ) and PEITC ( $\square$ ) on biomass formation (a) and metabolic activity (b) of E. coli, P. aeruginosa, S. aureus and L. monocytogenes. *no prevention on biofilm formation was found. Mean values \pm standard deviation for at least three replicates are illustrated. 
Table 3

Biofilm formation ability according to the classification proposed by Stepanović et al. (2000) and used in this study to characterize the biofilm preventive action of AITC and PEITC.

\begin{tabular}{llll}
\hline & Control & AITC & PEITC \\
\hline E. coli & +++ & + & +++ \\
P. aeruginosa & +++ & 0 & +++ \\
S. aureus & + & + & 0 \\
L. monocytogenes & ++ & 0 & ++ \\
\hline
\end{tabular}

(0) non-biofilm producer; $(+)$ weak biofilm producer; $(++)$ moderate biofilm producer; $(+++)$ strong biofilm producer.

roots of Korean and Japanese wasabi against six foodborne pathogenic bacteria, including E. coli 0157:H7 ATCC 43889 (MBC of $660 \mu \mathrm{g} \mathrm{mL}^{-1}$ ) and $S$. aureus ATCC 25923 (MBC of $5210 \mu \mathrm{g} \mathrm{mL}^{-1}$ ). Lin et al. (2000b) evaluated the activity of AITC against species of $E$. coli and $L$. monocytogenes and found that $500 \mu \mathrm{g} \mathrm{mL} \mathrm{m}^{-1}$ and $2500 \mu \mathrm{g} \mathrm{mL}^{-1}$, respectively, were required to inhibit the bacterial growth.

Due to the different susceptibilities of planktonic bacteria to AITC and PEITC, a concentration of $1000 \mu \mathrm{g} \mathrm{mL}^{-1}$ was selected to test in bacterial motility, adhesion and biofilm studies (prevention and control). In fact, phytochemical products are routinely classified as antimicrobials on the basis of susceptibility tests that produce growth inhibitory effects in the range of $100-1000 \mu \mathrm{g} \mathrm{mL}^{-1}$ (Tegos et al., 2002).
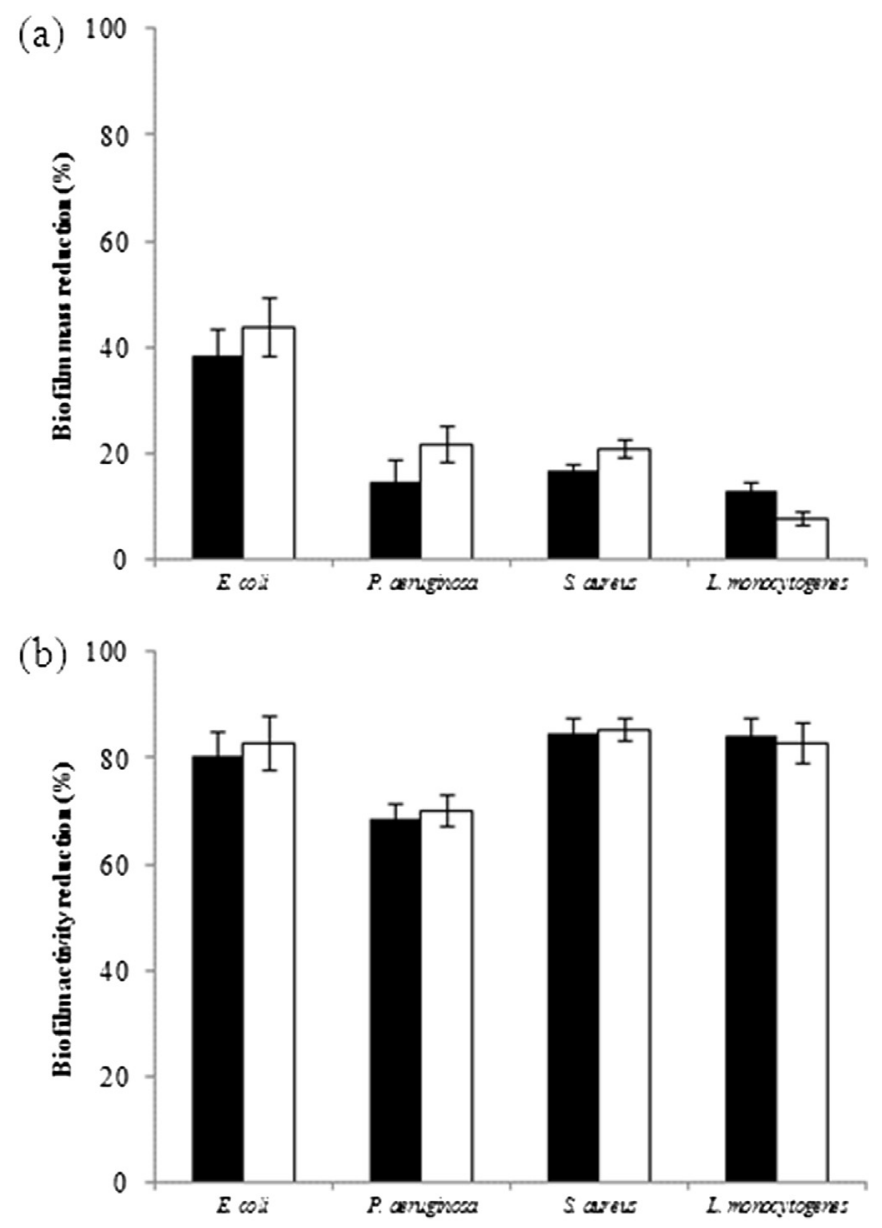

Fig. 4. Percentage of biomass reduction (a) and inactivation (b) of E. coli, P. aeruginosa, S. aureus and L. monocytogenes biofilms treated with AITC $(\mathbf{\square})$ and PEITC $(\square)$ for $1 \mathrm{~h}$. Mean values \pm standard deviation for at least three replicates are illustrated.
Three forms of surface motility, swimming, twitching and swarming, are documented for P. aeruginosa (Rashid and Kornberg, 2000; Déziel et al., 2001; Kearns et al., 2001; Overhage et al., 2008). $P$. aeruginosa swims by means of flagella, and during biofilm formation, swimming motility is involved in initial location and adherence to solid surfaces (O'Toole and Kolter, 1998). After surface attachment, $P$. aeruginosa moves by surface motility known as twitching (Kearns et al., 2001). E. coli has two flagella-driven motility types, swimming and swarming (Harshey, 2003; GómezGómez et al., 2007; Inoue et al., 2007). L. monocytogenes can also swimming by means of flagella-based motility to access nutrient sources. Swarming motility in L. monocytogenes is a phenotype that has been shown to contribute to the ability to adhere to intestinal epithelial cells (Gründling et al., 2004; Gray et al., 2006; Roberts et al., 2009). Although S. aureus is a non-flagellated Gram-positive bacterium, they can spread on solid surfaces by a motility phenomenon defined as colony spreading (Henrichsen, 1972; Tsompanidou et al., 2011). This bacterial movement is independent of flagella or pili and is apparently similar to sliding (a form of passive bacterial movement). Generally, the ability to spread is evaluated on soft agar plates (Kaito and Sekimizu, 2007; Tsompanidou et al., 2011). In this work it was found that AITC and PEITC affected the motility of the tested bacteria and, in general, PEITC was more efficient in motility reduction than AITC. Motility inhibition was not apparently due to bactericidal effects. In fact, motility tests were also performed, for all the bacteria, with AITC and PEITC at the MBC and at $100 \mu \mathrm{g} \mathrm{mL}^{-1}$. The results obtained were similar $(P>0.05)$ when the effects of the different concentrations were compared (data not shown). Therefore, AITC and PEITC affected bacterial motility to the same extent for concentrations below and at the $\mathrm{MBC}$, reinforcing that inhibition of viability and motility are different phenomena. This motility effect is apparently related with the cell state of the bacteria. A motile cell senses stimuli and alters the functioning of its motility machinery to improve its chances of migrating to a better location (Jarrell and McBride, 2008). In fact, motility plays a major role in the transition from planktonic to surface-associated life-style (O'Toole and Kolter, 1998). Therefore, the inhibition of bacterial motility can represent an important strategy to control biofilms. Furthermore bacteria in a motile state undergo alterations in their morphology which distinguishes them from their planktonic state (Julkowska et al., 2004). Lai et al. (2009) found increased resistance of swarming bacteria compared with their planktonic counterparts.

In addition to motility it is necessary to understand other factors that are involved in biofilm development, such as the initial adhesion process. Bacterial adhesion to surfaces has been studied extensively over the past decades in many diverse areas (Simões et al., 2010a, 2011a). Adhesion is a complex process that is affected by many factors including the physicochemical characteristics of bacteria, the material surface properties, and the environmental factors. The biological properties of bacteria, such as the presence of fimbriae and flagella and the production of extracellular polymeric substances, also influence attachment to surfaces (An and Friedman, 1998; Machado et al., 2011). In this work, the effects of AITC and PEITC at $1000 \mu \mathrm{g} \mathrm{mL}$, on the adhesion potential of bacteria to PS was determined by the characterization of the free energy of adhesion according to a thermodynamic approach (Van Oss et al., 1987, 1989). Similarly to previous studies, PS was used as a model surface for adhesion and biofilm formation (Simões et al., 2007, 2010a). Only for P. aeruginosa the free energy of adhesion was $<0 \mathrm{~mJ} \mathrm{~m}^{-2}$, in the absence of ITCs. When the bacteria were exposed to ITCs, an increase in the $\Delta \mathrm{G}_{\mathrm{iwI}}^{\mathrm{Tot}}$ value was found for $P$. aeruginosa (exposed to AITC and PEITC) and E. coli (exposed to AITC). A significant decrease in the $\Delta \mathrm{G}_{\mathrm{iwl}}^{\text {Tot }}$ value was found for $E$ coli (exposed to PEITC) and L. monocytogenes (exposed to AITC and 
PEITC). These distinct values of $\Delta \mathrm{G}_{\mathrm{iwl}}^{\text {Tot }}$ found after exposure to AITC and PEITC was apparently related to changes in the physicochemical cell surface properties as result of the presence of ITCs (data not shown). The electrophilic reactivity of ITCs (Cejpek et al., 2000; Verma, 2003; Luciano et al., 2008), seems to depend on the bacteria tested and on the molecule used. The electrophilic character of AITC and PEITC resulted in opposite effects when comparing the $\Delta G_{\text {iwI }}^{\text {Tot }}$ for Gram-positive (the free energy of adhesion decreased) and Gram-negative bacteria (the free energy of adhesion increased), except for E. coli exposed to PEITC. Therefore, it is expected that the ITCs may hinder the adhesion of bacteria to PS, particularly L. monocytogenes and S. aureus. Lee et al. (2012) demonstrated that AITC interferes with the expression of genes related to adhesion of S. aureus. Guiamet and Gómez De Saravia (2005), found that aqueous extracts of Brassica nigra, where the main component is AITC, had good activity to reduce planktonic cell growth and the number of adhered cells of Pseudomonas sp. Similar results were obtained by Gómez De Saravia and Gaylarde (1998). In fact, ITCs have long been known to bind to the external proteins of cell membranes, thus causing growth inhibition and consequently the cell death, with poor or no penetration to the cell cytoplasm (Gómez De Saravia and Gaylarde, 1998; Troncoso et al., 2005).

AITC and PEITC had preventive action on biofilm formation in both biofilm formation and metabolic activity. This preventive action is apparently due to interference with bacterial viability, motility and surface properties. This is evident for E. coli, $P$. aeruginosa and L. monocytogenes exposed to AITC and S. aureus exposed to PEITC. The transition from a planktonic to a surfaceassociated life-style, initiates with the transportation (motility) and attachment (adhesion) of microorganisms to a particular substratum (O'Toole and Kolter, 1998). Once in contact with the substratum, bacterial adhesion can be mediated by forces such as hydrophobic interaction (Gilbert et al., 1991). Bacterial motility has also influence on adhesion and biofilm formation processes. For this reason motility inhibition can be correlated with a decreased ability of bacteria to form biofilms. Shrout et al. (2006) demonstrated that differences in surface motility could explain differences in biofilm structure at the early stages of development.

For the control experiments, total biofilm removal was not achieved with AITC and PEITC. PEITC was more active than AITC in biofilm removal of $E$. coli, and both ITCs had similar effects in biofilm removal for the other bacteria. Also, biofilm activity inhibition occurred at higher levels than removal. The comparison of prevention and control results indicates that AITC and PEITC seem to prevent biofilm formation to a higher extent than the control effects (except for S. aureus grown in the presence of AITC and for $E$. coli and L. monocytogenes grown in the presence of PEITC). The higher preventive effects were also found for the biofilm activity of cells grown in the presence of AITC and PEITC, for all the bacteria. The comparison of biofilm removal and inactivation (in both biofilm prevention and control experiments) shows that these are distinct phenomena. Biofilms can be inactivated (with dead cells and/or dormant) but remain attached to the surface. Previous studies also demonstrated that biofilm removal and killing are distinct phenomena (Chen and Stewart, 2000; Simões et al., 2003, 2005; Sandasi et al., 2010; Borges et al., 2012). In fact, to our knowledge, the biofilm community has never assumed that inactivation of bacteria (either by killing or metabolic inactivation) signify that biofilm was removed, this include both bacteria and extracellular matrix (Borges et al., 2012). Moreover, other authors also found that although some compounds were able to inhibit cell attachment, the growth inhibition of a preformed biofilm was hard to achieve (Sandasi et al., 2010). To inhibit the growth of an already established biofilm (control) is more difficult to achieve than to inhibit the initial stage of biofilm formation, namely cell attachment (prevention) (Sandasi et al., 2010).

Volatile substances, like ITCs, do not influence processed food and can be safe preservatives (Al-Gendy et al., 2010). Additionally, these compounds have a strong antibacterial activity against foodborne pathogens (Aires et al., 2009a). These properties and the potential use of ITCs as natural preservatives in food industry can be an attractive alternative to synthetic products (Delaquis and Mazza, 1995; Jang et al., 2010). Also, in a recent report about the safety of AITC for the use as a food additive, the European Food Safety Authority (EFSA) Panel on Food Additives and Nutrient Sources added to Food (ANS) concluded that no significant safety concerns are expected with its use as anti-spoilage agent (EFSA, 2010). However, relatively little research has been carried out on the effect of ITCs on the growth of microbial biofilms. In this study, it was demonstrated that AITC and PEITC, in addition to planktonic antimicrobial action, had effects in the prevention and control of biofilms of $E$. coli, $L$. monocytogenes, $P$. aeruginosa and $S$. aureus. These effects are seemingly related to antimicrobial action, interference with bacterial motility and alteration of the cell surface properties.

\section{Conclusions}

AITC and PEITC demonstrated potential to inhibit the planktonic bacterial growth, cell motility and to change the cell surface properties. Also, the ITCs acted on biofilm prevention and control. To our knowledge this is the first study that demonstrates the preventive and biofilm control potential of AITC and PEITC on biofilms of $E$. coli, L. monocytogenes, $P$. aeruginosa and $S$. aureus. In fact, ITCs can be an eco-innovative intervention strategy to prevent and control biofilms, with immediate potential practical application in the food sector. Studies are in progress to evaluate the cytotoxicity of AITC and PEITC to mammalian cells and to ascertain the potential of these molecules to be used as antimicrobial therapeutic agents.

\section{Acknowledgments}

This work was supported by Operational Programme for Competitiveness Factors - COMPETE and by FCT - Portuguese Foundation for Science and Technology through Projects Bioresist PTDC/EBB-EBI/105085/2008; Phytodisinfectants - PTDC/DTP-SAP/ $1078 / 2012$ and the PhD grant awarded to Anabela Borges (SFRH/ $\mathrm{BD} / 63398 / 2009)$.

\section{References}

Abreu, A.C., McBain, A.J., Simões, M., 2012. Plants as sources of new antimicrobials and resistance-modifying agents. Natural Product Reports 29, 1007-1021.

Aires, A., Mota, V.R., Saavedra, M.J., Monteiro, A.A., Simões, M., Rosa, E.A.S., Bennett, R.N., 2009a. Initial in vitro evaluations of the antibacterial activities of glucosinolate enzymatic hydrolysis products against plant pathogenic bacteria. Journal of Applied Microbiology 106, 2096-2105.

Aires, A., Mota, V.R., Saavedra, M.J., Rosa, E.A.S., Bennett, R.N., 2009b. The antimicrobial effects of glucosinolates and their respective enzymatic hydrolysis products on bacteria isolated from the human intestinal tract. Journal of Applied Microbiology 106, 2086-2095.

Al-Gendy, A.A., El-gindi, O.D., Hafez, A.S., Ateya, A.M., 2010. Glucosinolates, volatile constituents and biological activities of Erysimum corinthium Boiss. (Brassicaceae). Food Chemistry 118, 519-524.

Al-Sohaibani, S., Murugan, K., 2012. Anti-biofilm activity of Salvadora persica on cariogenic isolates of Streptococcus mutans: in vitro and molecular docking studies. Biofouling 28, 29-38.

An, Y.H., Friedman, R.J., 1998. Concise review of mechanisms of bacterial adhesion to biomaterial surfaces. Journal of Biomedical Materials Research 43, 338-348.

Anderson, G.G., O'Toole, G.A., 2008. Innate and induced resistance mechanisms of bacterial biofilms. Current Topics in Microbiology and Immunology 322, 85-105.

Andersson, D.I., 2003. Persistence of antibiotic resistant bacteria. Current Opinion in Microbiology 6, 452-456. 
Andersson, D.I., Levin, B.R., 1999. The biological cost of antibiotic resistance. Current Opinion in Microbiology 2, 489-493.

Aslam, S., 2008. Effect of antibacterials on biofilms. American Journal of Infection Control 36, S175.e111-S175.e179.

Barbieri, G., Pernice, R., Maggio, A., De Pascale, S., Fogliano, V., 2008. Glucosinolates profile of Brassica rapa L. subsp. Sylvestris L. Janch. var. esculenta Hort. Food Chemistry 107, 1687-1691.

Berhow, M.A., Polat, U., Glinski, J.A., Glensk, M., Vaughn, S.F., Isbell, T., Ayala-Diaz, I., Marek, L., Gardner, C., 2012. Optimized analysis and quantification of glucosinolates from Camelina sativa seeds by reverse-phase liquid chromatography. Industrial Crops and Products 43, 119-125.

Borges, A., Saavedra, M.J., Simões, M., 2012. The activity of ferulic and gallic acids in biofilm prevention and control of pathogenic bacteria. Biofouling 28, 755-767.

Brown, K.K., Hampton, M.B., 2011. Biological targets of isothiocyanates. Biochimica et Biophysica Acta 1810, 888-894.

Busscher, H.J., Weerkamp, A.H., Van Der Mei, H.C., 1984. Measurement of the surface free energy of bacterial cell surfaces and its relevance for adhesion. Applied and Environmental Microbiology 48, 980-983.

Butler, M.T., Wang, Q., Harshey, R.M., 2010. Cell density and mobility protect swarming bacteria against antibiotics. Proceedings of the National Academy of Sciences of the United States of America 107, 3776-3781.

Cartea, M., Velasco, P., 2008. Glucosinolates in Brassica foods: bioavailability in food and significance for human health. Phytochemistry Reviews 7, 213-229.

Cejpek, K., Valusek, J., Velisek, J., 2000. Reactions of allyl isothiocyanate with alanine, glycine, and several peptides in model systems. Journal of Agricultural and Food Chemistry 48, 3560-3565.

Chen, H., Wang, C., Ye, J., Zhou, H., Chen, X., 2012. Antimicrobial activities of phenethyl isothiocyanate isolated from horseradish. Natural Product Research 26, 1016-1021.

Chen, X., Stewart, P.S., 2000. Biofilm removal caused by chemical treatments. Water Research 34, 4229-4233.

Clarke, D.B., 2010. Glucosinolates, structures and analysis in food. Analytical Methods 2, 310-325.

Conaway, C.C., Wang, C.X., Pittman, B., Yang, Y.M., Schwartz, J.E., Tian, D., McIntee, E.J., Hecht, S.S., Chung, F.L., 2005. Phenethyl isothiocyanate and sulforaphane and their $\mathrm{N}$-acetylcysteine conjugates inhibit malignant progression of lung adenomas induced by tobacco carcinogens in A/J mice. Cancer Research $65,8548-8557$.

Cos, P., Toté, K., Horemans, T., Maes, L., 2010. Biofilms: an extra hurdle for effective antimicrobial therapy. Current Pharmaceutical Design 16, 2279-2295.

D'Antuono, L.F., Elementi, S., Neri, R., 2009. Exploring new potential healthpromoting vegetables: glucosinolates and sensory attributes of rocket salads and related Diplotaxis and Eruca species. Journal of the Science of Food and Agriculture 89, 713-722.

Dalton, T., Cegielski, P., Akksilp, S., Asencios, L., Caoili, J.C., Cho, S.-N., Erokhin, V.V., Ershova, J., Gler, M.T., Kazennyy, B.Y., Kim, H.J., Kliiman, K., Kurbatova, E., Kvasnovsky, C., Leimane, V., van der Walt, M., Via, L.E., Volchenkov, G.V., Yagui, M.A., Kang, H., 2012. Prevalence of and risk factors for resistance to second-line drugs in people with multidrug-resistant tuberculosis in eight countries: a prospective cohort study. The Lancet 380, 1406-1417.

De Saravia, S.G.G., Guiamet, P.S., Videla, H.A., 2003. Prevention and Protection of the Effects of Biocorrosion and Biofouling Minimizing the Environmental Impact. Revista Metalurgia, Madrid, pp. 49-54.

Delaquis, P.J., Mazza, G., 1995. Antimicrobial properties of isothiocyanates in food preservation. Food Technology 49, 73-84.

Déziel, E., Comeau, Y., Villemur, R., 2001. Initiation of biofilm formation by Pseudomonas aeruginosa 57RP correlates with emergence of hyperpiliated and highly adherent phenotypic variants deficient in swimming, swarming, and twitching motilities. Journal of Bacteriology 183, 1195-1204.

Donlan, R.M., Costerton, J.W., 2002. Biofilms: survival mechanisms of clinically relevant microorganisms. Clinical Microbiology Reviews 15, 167-193.

EFSA, 2010. Panel on food additives and nutrient sources added to food (ANS). Scientific opinion on the safety of allyl isothiocyanate for the proposed uses as a food additive. European Food Safety Authority Journal 8, 1943-1983.

Fahey, J.W., Wade, K.L., Stephenson, K.K., Chou, F.E., 2003. Separation and purification of glucosinolates from crude plant homogenates by high-speed countercurrent chromatography. Journal of Chromatography A 996, 85-93.

Fahey, J.W., Zalcmann, A.T., Talalay, P., 2001. The chemical diversity and distribution of glucosinolates and isothiocyanates among plants. Phytochemistry 56, 5-51.

Ferreira, C., Pereira, A.M., Pereira, M.C., Melo, L.F., Simões, M., 2011. Physiological changes induced by the quaternary ammonium compound benzyldimethyldodecylammonium chloride on Pseudomonas fluorescens. Journal of Antimicrobial Chemotherapy 66, 1036-1043.

Gilbert, P., Evans, D.J., Evans, E., Duguid, I.G., Brown, M.R.W., 1991. Surface characteristics and adhesion of Escherichia coli and Staphylococcus epidermidis. Journal of Applied Bacteriology 71, 72-77.

Gilbert, P., McBain, A.J., Rickard, A.H., 2003. Formation of microbial biofilm in hygienic situations: a problem of control. International Biodeterioration and Biodegradation 51, 245-248.

Gómez-Gómez, J.M., Manfredi, C., Alonso, J.C., Blázquez, J., 2007. A novel role for RecA under non-stress: promotion of swarming motility in Escherichia coli K-12. BMC Biology 5, 1-14.

Gómez De Saravia, S.G., Gaylarde, C.C., 1998. The antimicrobial activity of an aqueous extract of Brassica negra. International Biodeterioration and Biodegradation 41, $145-148$.
Gray, M.J., Freitag, N.E., Boor, K.J., 2006. How the bacterial pathogen Listeria monocytogenes mediates the switch from environmental Dr. Jekyll to pathogenic Mr. Hyde. Infection and Immunity 74, 2506-2512.

Grubb, C.D., Abel, S., 2006. Glucosinolate metabolism and its control. Trends in Plant Science $11,89-100$.

Gründling, A., Burrack, L.S., Bouwer, H.G.A., Higgins, D.E., 2004. Listeria monocytogenes regulates flagellar motility gene expression through MogR, a transcriptional repressor required for virulence. Proceedings of the Nationa Academy of Sciences of the United States of America 101, 12318-12323.

Guiamet, P.S., Gómez De Saravia, S.G., 2005. Laboratory studies of biocorrosion control using traditional and environmentally friendly biocides: an overview. Latin American Applied Research 35, 295-300.

Guillemot, D., 1999. Antibiotic use in humans and bacterial resistance. Current Opinion in Microbiology 2, 494-498.

Halkier, B.A., Du, L., 1997. The biosynthesis of glucosinolates. Trends in Plant Science 2, 425-431.

Halkier, B.A., Gershenzon, J., 2006. Biology and biochemistry of glucosinolates. Annual Review of Plant Biology 57, 303-333.

Hall-Stoodley, L., Costerton, J.W., Stoodley, P., 2004. Bacterial biofilms: from the natural environment to infectious diseases. Nature Reviews Microbiology 2. 95-108.

Harshey, R.M., 2003. Bacterial motility on a surface: many ways to a common goal. Annual Review of Microbiology 57, 249-273.

Henrichsen, J., 1972. Bacterial surface translocation: a survey and a classification. Bacteriological Reviews 36, 478-503.

Holst, B., Williamson, G., 2004. A critical review of the bioavailability of glucosinolates and related compounds. Natural Product Reports 21, 425-447.

Hong, E., Kim, G.H., 2008. Anticancer and antimicrobial activities of $\beta$-phenylethyl isothiocyanate in Brassica rapa L. Food Science and Technology Research 14 377-382.

Inoue, T., Shingaki, R., Hirose, S., Waki, K., Mori, H., Fukui, K., 2007. Genome-wide screening of genes required for swarming motility in Escherichia coli K-12. Journal of Bacteriology 189, 950-957.

Jacob, C., Anwar, A., 2008. The chemistry behind redox regulation with a focus on sulphur redox systems. Physiologia Plantarum 133, 469-480.

Jagani, S., Chelikani, R., Kim, D.S., 2009. Effects of phenol and natural phenolic compounds on biofilm formation by Pseudomonas aeruginosa. Biofouling 25 321-324.

Janczuk, B., Chibowski, E., Bruque, J.M., Kerkeb, M.L., Caballero, F.G., 1993. On the consistency of surface free energy components as calculated from contact angles of different liquids: an application to the cholesterol surface. Journal of Colloid and Interface Science 159, 421-428.

Jang, M., Hong, E., Kim, G.H., 2010. Evaluation of antibacterial activity of 3-butenyl, 4-pentenyl, 2-phenylethyl, and benzyl isothiocyanate in Brassica vegetables. Journal of Food Science 75, M412-M416.

Jarrell, K.F., McBride, M.J., 2008. The surprisingly diverse ways that prokaryotes move. Nature Reviews Microbiology 6, 466-476.

Jiang, L.M., Hoogenkamp, M.A., Van Der Sluis, L.W.M., Wesselink, P.R., Crielaard, W., Deng, D.M., 2011. Resazurin metabolism assay for root canal disinfectant evaluation on dual-species biofilms. Journal of Endodontics 37, 31-35.

Julkowska, D., Obuchowski, M., Holland, I.B., Séror, S.J., 2004. Branched swarming patterns on a synthetic medium formed by wild-type Bacillus subtilis strain 3610: detection of different cellular morphologies and constellations of cells as the complex architecture develops. Microbiology 150, 1839-1849.

Kaito, C., Sekimizu, K., 2007. Colony spreading in Staphylococcus aureus. Journal of Bacteriology 189, 2553-2557.

Kearns, D.B., Robinson, J., Shimkets, L.J., 2001. Pseudomonas aeruginosa exhibits directed twitching motility up phosphatidylethanolamine gradients. Journal of Bacteriology 183, 763-767.

Kim, M.G., Lee, H.S., 2009. Growth-inhibiting activities of phenethyl isothiocyanate and its derivatives against intestinal bacteria. Journal of Food Science 74, M467-M471.

Kolm, R.H., Danielson, U.H., Zhang, Y., Talalay, P., Mannervik, B., 1995. Isothiocyanates as substrates for human glutathione transferases: structure-activity studies. Biochemical Journal 311, 453-459.

Lai, S., Tremblay, J., Déziel, E., 2009. Swarming motility: a multicellular behaviour conferring antimicrobial resistance. Environmental Microbiology 11, 126-136.

Lee, H.-Y., Zou, Y., Ahn, J., 2012. Physiochemical and molecular properties of antimicrobial-exposed Staphylococcus aureus during the planktonic-to-biofilm transition. Annals of Microbiology, 1-5.

Lin, C.M., Kim, J., Du, W.X., Wei, C.I., 2000a. Bactericidal activity of isothiocyanate against pathogens on fresh producer. Journal of Food Protection 63, 25-30.

Lin, C.M., Preston Iii, J.F., Wei, C.I., 2000b. Antibacterial mechanism of allyl isothiocyanate. Journal of Food Protection 63, 727-734.

Luciano, F.B., Hosseinian, F.S., Beta, T., Holley, R.A., 2008. Effect of free-SH containing compounds on allyl isothiocyanate antimicrobial activity against Escherichia coli 0157:H7. Journal of Food Science 73, M214-M220.

Machado, I., Graça, J., Sousa, A.M., Lopes, S.P., Pereira, M.O., 2011. Effect of antimicrobial residues on early adhesion and biofilm formation by wild-type and benzalkonium chloride-adapted Pseudomonas aeruginosa. Biofouling 27, 1151-1159.

Mah, T.F.C., O’Toole, G.A., 2001. Mechanisms of biofilm resistance to antimicrobial agents. Trends in Microbiology 9, 34-39.

Masuda, H., Harada, Y., Kishimoto, N., Tano, T., 2001. Antimicrobial activities of isothiocyanates. In: Aroma Active Compounds in Foods. ACS Symposium Series, vol. 794, pp. 229-250. 
Monroe, S., Polk, R., 2000. Antimicrobial use and bacterial resistance. Current Opinion in Microbiology 3, 496-501.

Munday, R., Mhawech-Fauceglia, P., Munday, C.M., Paonessa, J.D., Tang, L., Munday, J.S., Lister, C., Wilson, P., Fahey, J.W., Davis, W., Zhang, Y., 2008. Inhibition of urinary bladder carcinogenesis by broccoli sprouts. Cancer Research 68, 1593-1600.

Newman, D.J., Cragg, G.M., 2007. Natural products as sources of new drugs over the last 25 years. Journal of Natural Products 70, 461-477.

O'Toole, G.A., Kolter, R., 1998. Flagellar and twitching motility are necessary for Pseudomonas aeruginosa biofilm development. Molecular Microbiology 30 295-304.

Overhage, J., Bains, M., Brazas, M.D., Hancock, R.E.W., 2008. Swarming of Pseudomonas aeruginosa is a complex adaptation leading to increased production of virulence factors and antibiotic resistance. Journal of Bacteriology 190, 2671-2679.

Pettit, R.K., Weber, C.A., Pettit, G.R., 2009. Application of a high throughput Alamar blue biofilm susceptibility assay to Staphylococcus aureus biofilms. Annals of Clinical Microbiology and Antimicrobials 8.

Prior, R.L., Cao, G., 2000. Antioxidant phytochemicals in fruits and vegetables: diet and health implications. HortScience 35, 588-592.

Rashid, M.H., Kornberg, A., 2000. Inorganic polyphosphate is needed for swimming, swarming, and twitching motilities of Pseudomonas aeruginosa. Proceedings of the National Academy of Sciences of the United States of America 97, 4885-4890.

Rhee, M.S., Lee, S.Y., Dougherty, R.H., Kang, D.H., 2003. Antimicrobial effects of mustard flour and acetic acid against Escherichia coli 0157:H7, Listeria monocytogenes, and Salmonella enterica serovar Typhimurium. Applied and Environmental Microbiology 69, 2959-2963.

Roberts, A.J., Williams, S.K., Wiedmann, M., Nightingale, K.K., 2009. Some Listeria monocytogenes outbreak strains demonstrate significantly reduced invasion, inlA transcript levels, and swarming motility in vitro. Applied and Environmental Microbiology 75, 5647-5658.

Saavedra, M.J., Borges, A., Dias, C., Aires, A., Bennett, R.N., Rosa, E.S., Simões, M., 2010. Antimicrobial activity of phenolics and glucosinolate hydrolysis products and their synergy with streptomycin against pathogenic bacteria. Medicinal Chemistry 6, 174-183.

Sandasi, M., Leonard, C.M., Viljoen, A.M., 2010. The in vitro antibiofilm activity of selected culinary herbs and medicinal plants against Listeria monocytogenes. Letters in Applied Microbiology 50, 30-35.

Sarker, S.D., Nahar, L., Kumarasamy, Y., 2007. Microtitre plate-based antibacterial assay incorporating resazurin as an indicator of cell growth, and its application in the in vitro antibacterial screening of phytochemicals. Methods 42, 321-324.

Shin, I.S., Masuda, H., Naohide, K., 2004. Bactericidal activity of wasabi (Wasabia japonica) against Helicobacter pylori. International Journal of Food Microbiology 94, 255-261

Shrout, J.D., Chopp, D.L., Just, C.L., Hentzer, M., Givskov, M., Parsek, M.R., 2006. The impact of quorum sensing and swarming motility on Pseudomonas aeruginosa biofilm formation is nutritionally conditional. Molecular Microbiology 62, 1264-1277.

Simões, L.C., Lemos, M., Pereira, A.M., Abreu, A.C., Saavedra, M.J., Simões, M., 2011a. Persister cells in a biofilm treated with a biocide. Biofouling 27, 403-411.

Simões, L.C., Simões, M., Vieira, M.J., 2007. Biofilm interactions between distinct bacterial genera isolated from drinking water. Applied and Environmental Microbiology 73, 6192-6200.

Simões, L.C., Simões, M., Vieira, M.J., 2010a. Adhesion and biofilm formation on polystyrene by drinking water-isolated bacteria. Antonie van Leeuwenhoek. International Journal of General and Molecular Microbiology 98, 317-329.

Simões, L.C., Simões, M., Vieira, M.J., 2010b. Influence of the diversity of bacteria isolates from drinking water on resistance of biofilms to disinfection. Applied and Environmental Microbiology 76, 6673-6679.

Simões, L.C., Simões, M., Vieira, M.J., 2011b. The effects of metabolite molecules produced by drinking water-isolated bacteria on their single and multispecies biofilms. Biofouling 27, 685-699.
Simões, M., 2011. Antimicrobial strategies effective against infectious bacterial biofilms. Current Medicinal Chemistry 18, 2129-2145.

Simões, M., Bennett, R.N., Rosa, E.A., 2009. Understanding antimicrobial activities of phytochemicals against multidrug resistant bacteria and biofilms. Natural Product Reports 26, 746-757.

Simões, M., Pereira, M.O., Vieira, M.J., 2003. Effect of different concentrations of ortho-phthalaldehyde on biofilms formed by Pseudomonas fluorescens under different flow conditions. Biofouling 19, 287-295.

Simões, M., Pereira, M.O., Vieira, M.J., 2005. Action of a cationic surfactant on the activity and removal of bacterial biofilms formed under different flow regimes. Water Research 39, 478-486.

Simões, M., Rocha, S., Coimbra, M.A., Vieira, M.J., 2008a. Enhancement of Escherichia coli and Staphylococcus aureus antibiotic susceptibility using sesquiterpenoids. Medicinal Chemistry 4, 616-623.

Simões, M., Simões, L.C., Cleto, S., Pereira, M.O., Vieira, M.J., 2008b. The effects of a biocide and a surfactant on the detachment of Pseudomonas fluorescens from glass surfaces. International Journal of Food Microbiology 121, 335-341.

Simões, M., Simões, L.C., Machado, I., Pereira, M.O., Vieira, M.J., 2006. Control of flow-generated biofilms with surfactants: evidence of resistance and recovery. Food and Bioproducts Processing 84, 338-345.

Sofrata, A., Santangelo, E.M., Azeem, M., Borg-Karlson, A.K., Gustafsson, A., Pütsep, K., 2011. Benzyl isothiocyanate, a major component from the roots of Salvadora persica is highly active against gram-negative bacteria. PLoS ONE 6 .

Stepanović, S., Vuković, D., Dakić, I., Savić, B., Švabić-Vlahović, M., 2000. A modified microtiter-plate test for quantification of staphylococcal biofilm formation. Journal of Microbiological Methods 40, 175-179.

Stewart, P.S., Costerton, J.W., 2001. Antibiotic resistance of bacteria in biofilms. Lancet 358, 135-138.

Stickland, H.G., Davenport, P.W., Lilley, K.S., Griffin, J.L., Welch, M., 2010. Mutation of nfxB causes global changes in the physiology and metabolism of Pseudomonas aeruginosa. Journal of Proteome Research 9, 2957-2967.

Tegos, G., Stermitz, F.R., Lomovskaya, O., Lewis, K., 2002. Multidrug pump inhibitors uncover remarkable activity of plant antimicrobials. Antimicrobial Agents and Chemotherapy 46, 3133-3141.

Toté, K., Horemans, T., Vanden Berghe, D., Maes, L., Cos, P., 2010. Inhibitory effect of biocides on the viable masses and matrices of Staphylococcus aureus and Pseudomonas aeruginosa biofilms. Applied and Environmental Microbiology 76, 3135-3142.

Troncoso, R., Espinoza, C., Sánchez-Estrada, A., Tiznado, M.E., García, H.S., 2005. Analysis of the isothiocyanates present in cabbage leaves extract and their potential application to control Alternaria rot in bell peppers. Food Research International 38, 701-708.

Tsompanidou, E., Sibbald, M.J.J.B., Chlebowicz, M.A., Dreisbach, A., Back, J.W., Van Dijl, J.M., Buist, G., Denham, E.L., 2011. Requirement of the agr locus for colony spreading of Staphylococcus aureus. Journal of Bacteriology 193, 1267-1272.

Van Oss, C.J., Chaudhury, M.K., Good, R.J., 1987. Monopolar surfaces. Advances in Colloid and Interface Science 28, 35-64.

Van Oss, C.J., Good, R.J., Chaudhury, M.K., 1988. Additive and nonadditive surface tension components and the interpretation of contact angles. Langmuir 4 , 884-891.

Van Oss, C.J., Ju, L., Chaudhury, M.K., Good, R.J., 1989. Estimation of the polar parameters of the surface tension of liquids by contact angle measurements on gels. Journal of Colloid and Interface Science 128, 313-319.

Verma, R.P., 2003. Synthesis and reactions of 3-oxobutyl isothiocyanate (OB ITC). European Journal of Organic Chemistry, 415-420.

Walsh, C., 2000. Molecular mechanisms that confer antibacterial drug resistance. Nature 406, 775-781.

Zhang, Y., 2012. The molecular basis that unifies the metabolism, cellular uptake and chemopreventive activities of dietary isothiocyanates. Carcinogenesis 33, 2-9.

Zou, Y., Woo, J., Ahn, J., 2012. Cellular and molecular responses of Salmonella Typhimurium to antimicrobial-induced stresses during the planktonic-tobiofilm transition. Letters in Applied Microbiology 55, 274-282. 